\title{
Sarcoidosis Under Dendritic Cell Vaccination Immunotherapy in Long-term Responding Patients with Metastatic Melanoma
}

\author{
UGUR USLU, MICHAEL ERDMANN, STEFAN SCHLIEP, JAN DÖRRIE, \\ NIELS SCHAFT, GEROLD SCHULER and BEATRICE SCHULER-THURNER \\ Friedrich-Alexander-University Erlangen-Nürnberg (FAU), \\ Department of Dermatology, Universitätsklinikum Erlangen, Erlangen, Germany
}

\begin{abstract}
Sarcoidosis, a chronic inflammatory disorder, results from increased immune responses. Its development can be triggered in patients under immunotherapy, as activation of the immune system in these patients is desired. Since 1997, 249 patients with metastasized cutaneous melanoma (stage III and IV, AJCC 2009) have been treated with dendritic cell (DC)-based vaccines at our hospital. Three out of these patients were diagnosed with sarcoidosis after or during long-term DC vaccination therapy (1.20\%). Metastatic disease was initially suspected based on the radiographic manifestation of lung masses or bilateral hilar lymphadenopathy. Histological assessment, however, revealed the appropriate diagnosis. Interestingly, all three patients are long-term responders and have remained free of metastatic or progressive disease for over a period of at least 4 years. In summary, sarcoidosis can occur in patients with cancer who have benefited from DC-based therapeutic vaccination and thus, its development, even with substantial delay, may be associated with successful anticancer immunotherapy.
\end{abstract}

Firstly described by Ralph M. Steinman (1), dendritic cells (DCs) are known to play a crucial role in immune responses (2). The ex vivo generation of autologous DCs allows their maturation and loading with e.g. tumor-specific antigens for cancer immunotherapy (3-5). These DCs are then re-injected into the patients in order to induce an antitumor immune response (3-6). Indeed, clinical studies in patients suffering

Correspondence to: Dr. med. Ugur Uslu, MD, Friedrich-AlexanderUniversity Erlangen-Nürnberg (FAU), Department of Dermatology, Universitätsklinikum Erlangen, Ulmenweg 18, D-91054 Erlangen, Germany. Tel: +49 91318545833, Fax: +49 91318536152, e-mail: ugur.uslu@uk-erlangen.de

Key Words: Cancer, clinical trial, granuloma, granulomatosis, Th1 response. from melanoma and other tumor types showed that patients benefited from this approach $(3,4,6-8)$.

Adverse events in patients receiving DC-vaccination therapy are commonly seen and include flu-like symptoms, chills and fatigue, as well as local reactions, such as pruritus at injection sites $(3,9)$. Compared to other immunotherapeutic agents approved for advanced-stage malignancies, e.g. antibodies for checkpoint blockade, where grade III-IV adverse events are frequently seen (10-13), the adverse events in DC vaccination therapy are mainly grade I-II $(3,9)$. Thus, therapeutic DC vaccination represents a safe and welltolerated method.

Sarcoidosis, which is a chronic inflammatory disorder of unknown etiology and which can affect any organ system (14), has been described in patients under immunotherapy (15-19).

Sarcoidosis is histologically characterized by accumulation of T-lymphocytes, mononuclear phagocytes, and formation of non-caseating granulomas $(20,21)$. Its incidence varies with geographical regions and is described in Western countries at $10-20 / 100,000$ inhabitants $(14,20-22)$. Young people between 20 and 50 years are mainly affected, male and female similarly $(14,20-22)$. Other diseases that can clinically present like sarcoidosis include tuberculosis, fungal infections, primary neoplasms, and metastases (14, 20-22).

As sarcoidosis is assumed to result from increased immune responses and T-cell activation (14, 20-22), its development can be triggered in patients under immunotherapy, as activation of the immune system in these patients is induced. Thus, the development of sarcoidosis may also be associated with clinical benefit in these patients. In a study performed by Lheure et al., five out of 70 patients with metastatic melanoma under therapy with the B-Raf proto-oncogene (BRAF)inhibitor vemurafenib developed sarcoidosis (23). Indeed, all five patients seemed to have better clinical outcomes: two showed complete remission and three partial remission (23). Bordry et al. described a long-term surviving patient with metastatic melanoma who developed pulmonary sarcoid-like 
Table I. Patient characteristics including features of their melanoma and dendritic cell (DC) vaccination therapy.

\begin{tabular}{|c|c|c|c|c|c|c|}
\hline Patient, gender & Disease & Metastases & $\begin{array}{l}\text { Age upon } \\
\text { diagnosis }\end{array}$ & $\begin{array}{l}\text { Previous } \\
\text { treatment }\end{array}$ & $\begin{array}{c}\text { Total } \\
\text { vaccination } \\
\text { cycles }\end{array}$ & $\begin{array}{l}\text { DC response, } \\
\text { status }\end{array}$ \\
\hline Patient 1 , female & $\begin{array}{l}\text { Melanoma of } \\
\text { unknown primary }\end{array}$ & $\begin{array}{l}\text { Lymph nodes, lung, } \\
\text { adrenal gland }\end{array}$ & 65 Years & Dacarbazine & $\begin{array}{l}25 \text { (over a period of } \\
10 \text { years; ended) }\end{array}$ & $\begin{array}{l}\text { Progression-free for } \\
12 \text { years, still alive }\end{array}$ \\
\hline Patient 2, male & $\begin{array}{l}\text { Superficial melanoma, } \\
\text { right thigh, } 0.8 \mathrm{~mm}, \mathrm{CL} \text { III }\end{array}$ & Lung & 69 Years & Dacarbazine & $\begin{array}{l}21 \text { (over a period of } \\
10 \text { years; ongoing) }\end{array}$ & $\begin{array}{l}\text { Complete remission of } \\
\text { lung metastases and } \\
\text { tumor-free for } 4 \text { years, } \\
\text { still alive }\end{array}$ \\
\hline Patient 3, female & $\begin{array}{c}\text { Nodular melanoma, } \\
\text { left scapula, } 4.8 \mathrm{~mm}, \mathrm{CL} \text { IV }\end{array}$ & $\begin{array}{l}\text { Lymph nodes, } \\
\text { lung }\end{array}$ & 64 Years & None & $\begin{array}{l}21 \text { (over a period of } \\
5 \text { years; ended) }\end{array}$ & $\begin{array}{l}\text { Tumor-free for } \\
8 \text { years, still alive }\end{array}$ \\
\hline
\end{tabular}

CL: Clark level.

granulomas after multiple therapeutic cancer vaccinations more than 10 years after the initiation of immunotherapy (19). Similarly, it is known that the development of vitiligo or flulike symptoms under immunotherapy is associated with a better clinical response rate $(9,24)$.

Given these findings and observations, here we report the development of sarcoidosis in three patients with metastatic melanoma receiving DC-based vaccines at our hospital, which could be associated with long-term anticancer response and clinical benefit. Additionally, we wish to highlight the significance of histopathological assessment in making the correct diagnosis, as in patients with cancer especially, the radiographic manifestation of sarcoidosis can mimic metastases.

Since 1997, we have treated a total of 249 patients with metastasized cutaneous melanoma, stage III and stage IV according to the American Joint Committee on Cancer (AJCC) 2009 (25), with at least four cycles of DC-based vaccines in different clinical trials or for compassionate use at the Department of Dermatology, University Hospital Erlangen, Germany. Clinical trials were approved by the appropriate Medical Ethical Review Board and regulatory authorities, and patients signed written informed consent forms after detailed oral and written explanation of the nature, significance, and consequence of the treatment. Every 3 months, follow-up imaging with magnetic resonance imaging of the brain and computed tomographic scan (CT) of the neck, chest and abdomen, in addition to full-body skin examinations and measurement of the serum tumor markers S100 and melanoma inhibitory activity (MIA)- protein were performed. Detailed analysis of medical reports revealed that three out of the 249 patients developed sarcoidosis during or after long-term vaccination therapy.

\section{Patients and Methods}

Patient 1. A 65-year-old female patient with metastatic melanoma was referred to our Department for DC vaccination therapy (Table I). The patient was diagnosed with melanoma lung metastases 3 years prior to this presentation, which were surgically removed, while a primary tumor was not identified. One year later, the patient underwent further surgeries for right axillary lymph node metastases (five out of 11 removed lymph nodes were metastatic), followed by adjuvant chemotherapy with dacarbazine. After 10 cycles of this therapy, however, the patient showed progression of disease, with metastasis in the left adrenal gland, underwent surgery, and presented at our Department. Vaccination therapy with monocyte-derived DCs loaded with mRNA encoding for melanoma-associated antigen 3 (MAGE-A3), melan A, and survivin within a clinical trial (NCT00074230) was started. At that time-point, the patient had a lesion in the right adrenal gland and enlarged abdominal lymph nodes. The patient received a total of 25 vaccinations over a period of 10 years without further progression of metastatic disease; the lesion in the right adrenal gland and the abdominal lymph nodes remained the same size. Vaccination therapy was ended and follow-up imaging every 3 months was continued. Approximately 2 years later, a suspicious mass in the right lung and bilateral hilar lymphadenopathy was noted on the CT scan of the chest (Figure 1). Progression of metastatic disease was suspected and surgical excision of the lung mass and hilar lymph nodes was performed. Histological assessment, however, revealed noncaseating epithelioid cell granulomas with Langhans giant cells and Schaumann bodies in polarized light (Figure 2). Ziehl Neelsen as well as Periodic acid-Schiff (PAS) and Grocott's methenamine silver staining excluded mycobacterial and fungal infections, respectively. Pan-melanoma staining for homatropine methylbromide 45 (HMB45), melan-A (MART1), and tyrosinase remained negative, therefore showing no evidence of melanoma metastases. Sarcoidosis was diagnosed given the radiographic manifestations and histological findings. As no clinical symptoms were reported by the patient and lung-function tests showed normal 

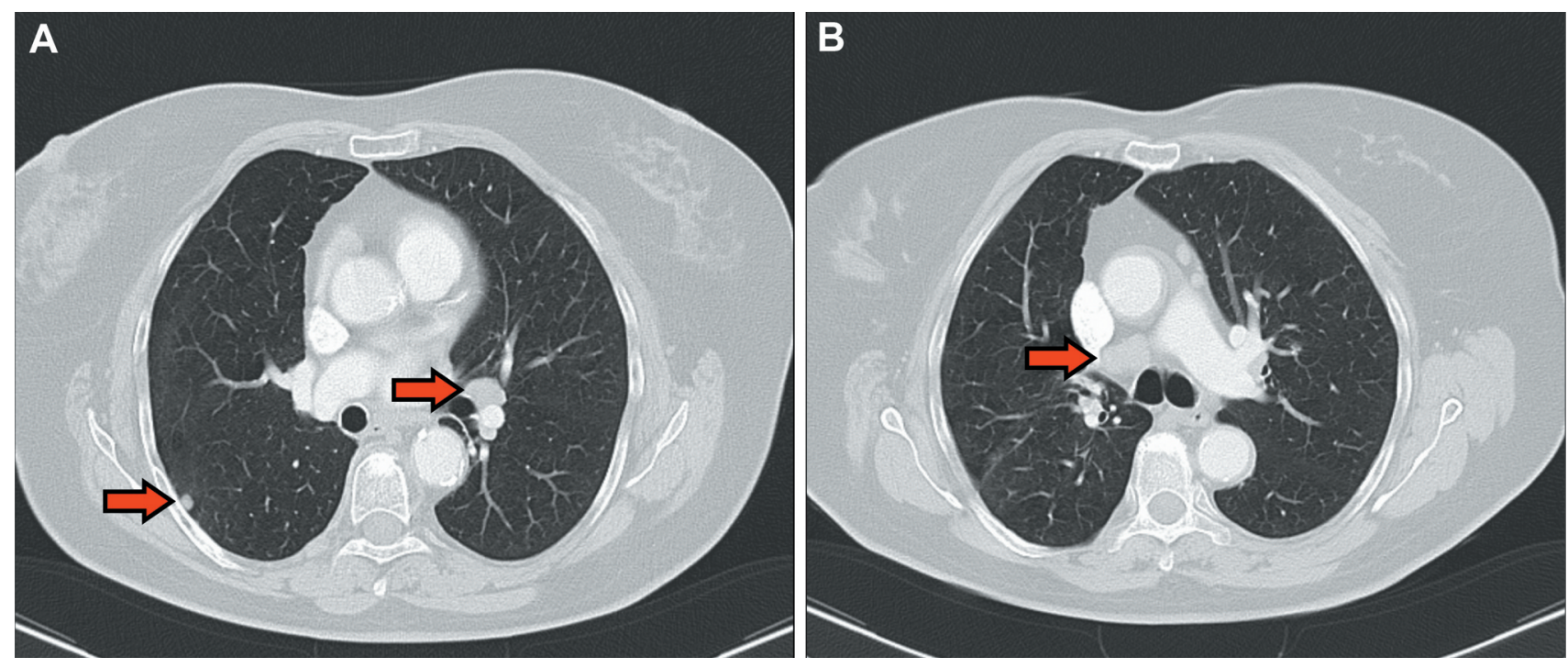

Figure 1. Radiographic manifestation of sarcoidosis. Computed tomographic scan of the chest revealed a notable mass in the right lung (A) and bilateral hilar lymphadenopathy $(A, B)$ (arrows).
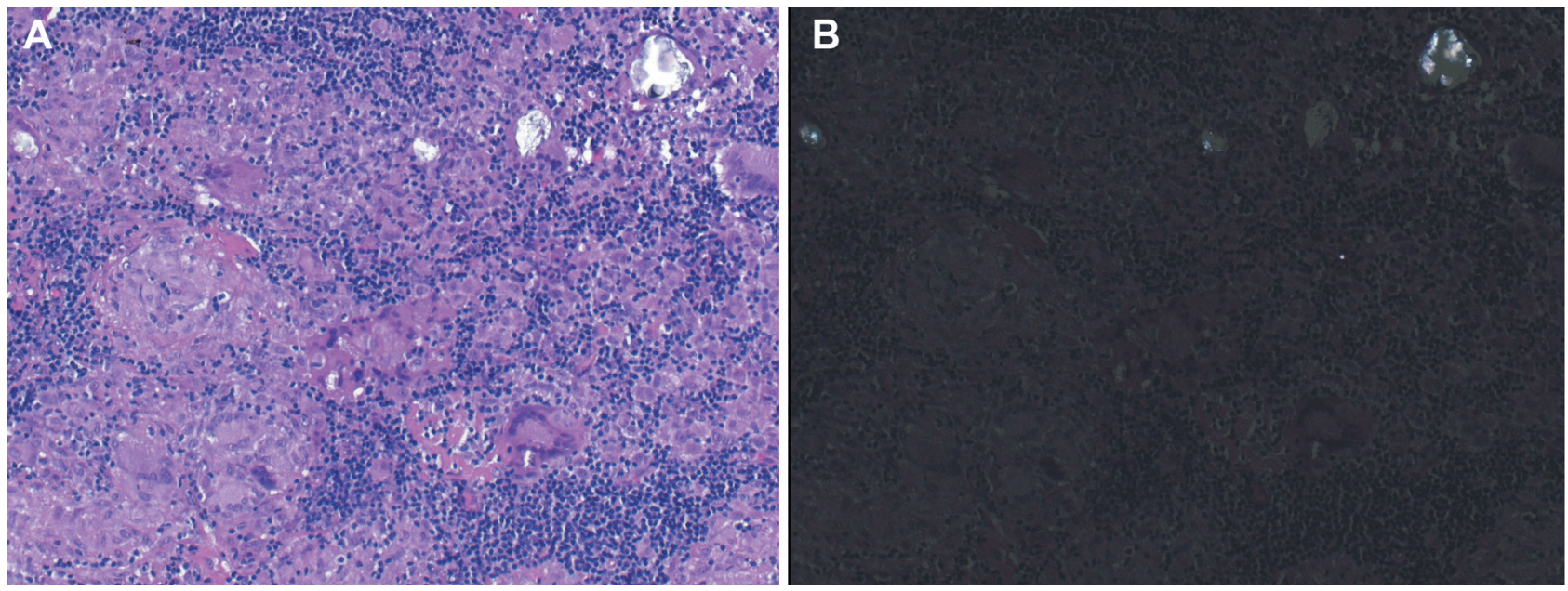

Figure 2. Histopathological assessment of tissue biopsy. Histology of biopsies showed at $\times 40$ magnification non-caseating epitheloid cell granulomas with Langhans giant cells by hematoxylin and eosin staining (A) and Schaumann bodies in polarized light (B), consistent with sarcoidosis.

diffusion capacity, only close follow-up has been performed to date. The patient remains free of symptoms or progression of metastatic disease (Figure 3 ).

Patient 2. A 69-year-old male patient presented with a superficial melanoma of the right thigh with a Breslow thickness of $0.8 \mathrm{~mm}$ (Table I). After excision of the primary tumor with a safety margin of $1 \mathrm{~cm}$, bilateral lung masses appeared on the CT scan of the chest only 3 months later. The patient was started on dacarbazine and received a total of 12 cycles, after which further enlargement of the lung masses was observed. Therefore, dacarbazine was stopped and vaccination therapy within the same clinical trial as patient 1 with tumorantigen loaded monocyte-derived DCs was started (NCT00074230). Under vaccination therapy, gradual tumor regression of the lung masses was seen, with complete remission after 5 years of DC vaccination therapy (Figure 3). Another 3 years later, however, bilateral hilar lymphadenopathy was noted on the CT scan of the chest. Bronchoscopy with bronchoalveolar lavage (BAL), as well as 


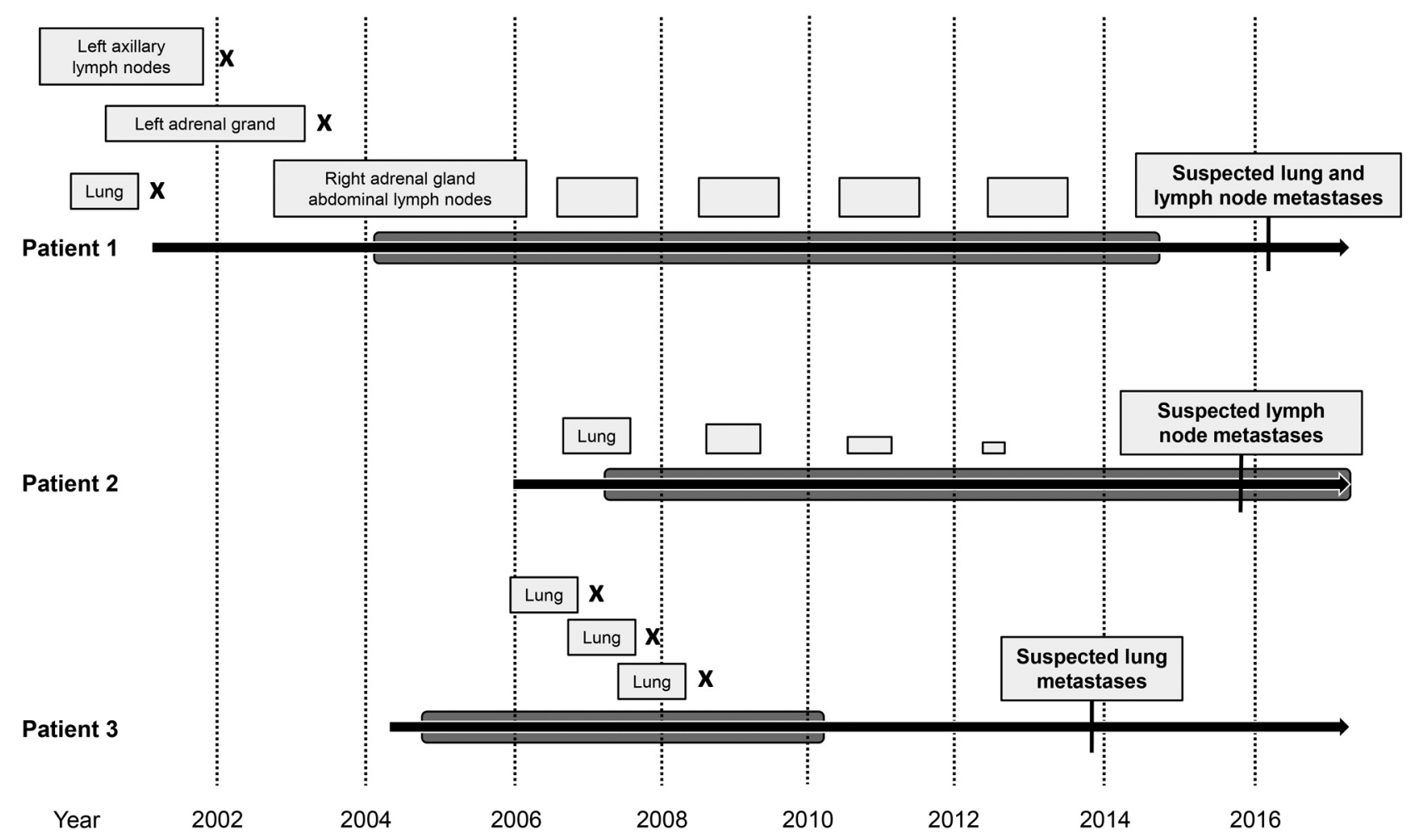

Figure 3. Clinical course of the individual patients. Black horizontal arrows indicate time from first melanoma diagnosis and dark gray bars mark the period during which the patients received immunotherapy with dendritic cells. Boxes indicate the masses or metastases patients developed. At time-points labeled with $X$, patients underwent surgical removal/stereotactic radiation therapy with complete remission of the metastases/masses.

transbronchial biopsy and needle aspiration was performed. Histological assessment of lymph nodes revealed noncaseating epithelioid granulomas negative by Ziehl Neelsen, PAS, Grocott's methenamine silver, and pan-melanoma stainings. Additionally, the BAL showed an elevated CD4/CD8 ratio of 15.3, consistent with sarcoidosis. No clinical symptoms were reported by the patient and lung function tests showed normal diffusion capacity. Close follow-up has been maintained. To date, the patient has received a total of 21 vaccinations over a period of 10 years and his follow-up has not revealed any signs of metastatic disease (Figure 3).

Patient 3. A 64-year-old female patient presented with a nodular melanoma of the left upper scapula with ulceration and a Breslow thickness of $4.8 \mathrm{~mm}$ (Table I). Excision of the primary tumor with a safety margin of $2 \mathrm{~cm}$ and a sentinel lymph node (SLN) biopsy were performed and revealed a positive left nuchal SLN. Adjuvant vaccination therapy with tumor-peptide loaded monocyte-derived DCs was initiated within a clinical trial (NCT00053391). Under vaccination therapy, the patient developed lung masses three times: two were treated with stereotactic radiation therapy and one was surgically removed (Figure 3). Histology of the surgically removed lung mass did not confirm melanoma metastasis, but showed signs of fibrotic pneumonitis with secondary bronchiectasis as a result of previous radiotherapy. Over a period of 5 years, the patient received a total of 21 vaccinations. Vaccination therapy was ended and follow-up imaging every 3 months was continued. Approximately 4 years later, a suspicious mass in the right lung was noted on the CT scan of the chest without signs of enlarged hilar or mediastinal lymph nodes. Surgical excision was performed. Histological assessment excluded melanoma metastasis or fungal infection and revealed noncaseating epithelioid cell granulomas negative on Ziehl Neelsen staining, consistent with sarcoidosis. No clinical symptoms were reported by the patient and lung function tests showed a normal diffusion capacity. The patient remains under close follow-up and free of symptoms or manifestation of metastatic disease (Figure 3).

\section{Discussion}

Three out of a total of 249 patients with metastatic melanoma have been diagnosed with sarcoidosis under or 
following immunotherapy with DC vaccines at our hospital, which represents $1.20 \%$ of the study population. As the prevalence for patients with melanoma to develop sarcoidosis was reported to be $0.58 \%$, and in the absence of any immunotherapy only $0.42 \%$ (26), immune induction by DC vaccination therapy could indeed have triggered the development of this chronic inflammatory disorder in our patients. It may be also possible that sarcoidosis could have occurred coincidentally or in association with the tumor itself and independent of the vaccination therapy (27). However, prior studies and cases have been published reporting on sarcoidosis development under immunotherapy with e.g. checkpoint-blockade antibodies in combination with or without DC vaccination therapy, as well as with interferonalpha (15-17). The true pathophysiological correlation remains unclear (15-18).

Although the etiology and pathogenesis of sarcoidosis is unknown, it has been shown that type 1 T-helper cells (Th1)mediated responses to antigens results in e.g. increased expression of interferon- $\gamma$ and tumor necrosis factor- $\alpha$ (14, 20-22). This promotes macrophage accumulation, activation and aggregation, and causes the development of granulomatous inflammation (14, 20-22). The aim of DC vaccination therapy is to induce an increased immune response directed against the tumor $(3,4,6-8)$. Thus, this may trigger sarcoidosis development by increased cytokine release of Th1 cells. As memory T-cell generation under DC vaccination therapy can result in a long-lasting antitumor effect and increased T-cell activity, sarcoidosis can occur, even if therapy was ended months or years before $(7,28)$. Indeed, all three patients reported here are long-term responders with a disease-free or progression-free interval of at least 4 years after therapy for advanced-stage melanoma (Figure 3, Table I). One patient even showed complete remission of his metastatic disease under vaccination therapy and has remained tumor free (Figure 3, Table I).

None of the three patients showed any clinical symptoms of sarcoidosis. They were diagnosed given typical radiographic manifestations on routine follow-up imaging and histological assessment. Other differential diagnoses, such as tuberculosis, fungal infection, and, most importantly, metastatic disease were excluded. Thus, histopathological assessment in addition to imaging and clinical findings is needed to make the correct diagnosis $(14,20-22,29,30)$. Upon sarcoidosis diagnosis, the risk-benefit balance should be considered in order to evaluate the necessity for discontinuation of anticancer therapy. In asymptomatic patients, DC vaccination therapy can be continued under regular follow-up. In the case of symptoms, however, immunotherapy should be stopped and appropriate systemic therapy (e.g. corticosteroids) should be started.

In conclusion, it may be difficult in patients with cancer with radiographic but asymptomatic manifestation of sarcoidosis to distinguish between benign and malignant disease. Histological assessment is needed to achieve this. We and others observed sarcoidosis primarily in those patients with metastatic melanoma who seemed to have benefited from immunotherapy, making it possible that development of sarcoidosis may be associated with effective anticancer immune response and long-term survival. Hence we encourage the reporting of further cases and studies since they are required to provide further confirmation of our observations.

\section{Acknowledgements}

The clinical trials referred to here were partially financed by the German Research Foundation (DFG) via Collaborative Research Center grant SFB 643 (C1).

\section{References}

1 Steinman RM and Cohn ZA: Identification of a novel cell type in peripheral lymphoid organs of mice. I. Morphology, quantitation, tissue distribution. J Exp Med 137: 1142-1162, 1973.

2 Steinman RM: The dendritic cell system and its role in immunogenicity. Annu Rev Immunol 9: 271-296, 1991.

3 Erdmann M and Schuler-Thurner B: Dendritic cell vaccines in metastasized malignant melanoma. G Ital Dermatol Venereol 143: 235-250, 2008.

4 Boudewijns S, Bloemendal M, Gerritsen WR, de Vries IJ and Schreibelt G: Dendritic cell vaccination in melanoma patients: From promising results to future perspectives. Hum Vaccin Immunother 12: 2523-2528, 2016.

5 Erdmann M, Dörrie J, Schaft N, Strasser E, Hendelmeier M, Kämpgen E, Schuler G and Schuler-Thurner B: Effective clinical-scale production of dendritic cell vaccines by monocyte elutriation directly in medium, subsequent culture in bags and final antigen loading using peptides or RNA transfection. J Immunother 30: 663-674, 2007.

6 Schuler-Thurner B, Dieckmann D, Keikavoussi P, Bender A, Maczek C, Jonuleit H, Röder C, Haendle I, Leisgang W, Dunbar R, Cerundolo V, von Den Driesch P, Knop J, Bröcker EB, Enk A, Kämpgen E and Schuler G: MAGE-3 and influenza-matrix peptide-specific cytotoxic T-cells are inducible in terminal stage HLA-A2.1+ melanoma patients by mature monocyte-derived dendritic cells. J Immunol 165: 3492-3496, 2000.

7 Wimmers F, Aarntzen EH, Duiveman-deBoer T, Figdor CG, Jacobs JF, Tel $\mathrm{J}$ and de Vries IJ: Long-lasting multifunctional CD8+ T-cell responses in end-stage melanoma patients can be induced by dendritic cell vaccination. Oncoimmunology 5: e1067745, 2016.

8 Prue RL, Vari F, Radford KJ, Tong H, Hardy MY, D'Rozario R, Waterhouse NJ, Rossetti T, Coleman R, Tracey C, Goossen H, Gounder V, Crosbie G, Hancock S, Diaz-Guilas S, Mainwaring $\mathrm{P}$, Swindle $\mathrm{P}$ and Hart DN: A phase I clinical trial of CD1c (BDCA-1)+ dendritic cells pulsed with HLA-A*0201 peptides for immunotherapy of metastatic hormone refractory prostate cancer. J Immunother 38: 71-76, 2015.

9 Boudewijns S, Westdorp H, Koornstra RH, Aarntzen EH, Schreibelt G, Creemers JH, Punt CJ, Figdor CG, de Vries IJ, 
Gerritsen WR and Bol KF: Immune-related adverse events of dendritic cell vaccination correlate with immunologic and clinical outcome in stage III and IV melanoma patients. J Immunother 39: 241-248, 2016.

10 Uslu U, Agaimy A, Hundorfean G, Harrer T, Schuler G and Heinzerling L: Autoimmune colitis and subsequent CMVinduced hepatitis after treatment with ipilimumab. J Immunother 38: 212-215, 2015.

11 Voskens CJ, Goldinger SM, Loquai C, Robert C, Kaehler KC, Berking C, Bergmann T, Bockmeyer CL, Eigentler T, Fluck M, Garbe C, Gutzmer R, Grabbe S, Hauschild A, Hein R, Hundorfean G, Justich A, Keller U, Klein C, Mateus C, Mohr P, Paetzold S, Satzger I, Schadendorf D, Schlaeppi M, Schuler G, Schuler-Thurner B, Trefzer U, Ulrich J, Vaubel J, von Moos R, Weder P, Wilhelm T, Göppner D, Dummer R and Heinzerling LM: The price of tumor control: an analysis of rare side-effects of anti-CTLA-4 therapy in metastatic melanoma from the Ipilimumab Network. PLoS One 8: e53745, 2013.

12 Hofmann L, Forschner A, Loquai C, Goldinger SM, Zimmer L, Ugurel S, Schmidgen MI, Gutzmer R, Utikal JS, Göppner D, Hassel JC, Meier F, Tietze JK, Thomas I, Weishaupt C, Leverkus M, Wahl R, Dietrich U, Garbe C, Kirchberger MC, Eigentler T, Berking C, Gesierich A, Krackhardt AM, Schadendorf D, Schuler G, Dummer R and Heinzerling LM: Cutaneous, gastrointestinal, hepatic, endocrine, and renal side-effects of antiPD-1 therapy. Eur J Cancer 60: 190-209, 2016.

13 Zimmer L, Goldinger SM, Hofmann L, Loquai C, Ugurel S, Thomas I, Schmidgen MI, Gutzmer R, Utikal JS, Göppner D, Hassel JC, Meier F, Tietze JK, Forschner A, Weishaupt C, Leverkus M, Wahl R, Dietrich U, Garbe C, Kirchberger MC, Eigentler T, Berking C, Gesierich A, Krackhardt AM, Schadendorf D, Schuler G, Dummer R and Heinzerling LM: Neurological, respiratory, musculoskeletal, cardiac and ocular side-effects of anti-PD-1 therapy. Eur J Cancer 60: 210-225, 2016.

14 Baughman RP, Teirstein AS, Judson MA, Rossman MD, Yeager H Jr, Bresnitz EA, DePalo L, Hunninghake G, Iannuzzi MC, Johns CJ, McLennan G, Moller DR, Newman LS, Rabin DL, Rose C, Rybicki B, Weinberger SE, Terrin ML, Knatterud GL and Cherniak R: Clinical characteristics of patients in a casecontrol study of sarcoidosis. Am J Respir Crit Care Med 164: 1885-1889, 2001.

15 Danlos FX, Pagès C, Baroudjian B, Vercellino L, Battistella M, Mimoun M, Jebali M, Bagot M, Tazi A and Lebbé C: Nivolumab-Induced sarcoid-like granulomatous reaction in a patient with advanced melanoma. Chest 149: e133-e136, 2016.

16 Heinzerling LM, Anliker MD, Müller J, Schlaeppi M and von Moos R: Sarcoidosis induced by interferon-alpha in melanoma patients: incidence, clinical manifestations, and management strategies. J Immunother 33: 834-839, 2010.

17 Wilgenhof S, Corthals J, Heirman C, van Baren N, Lucas S, Kvistborg P, Thielemans K and Neyns B: Phase II study of autologous monocyte-derived mRNA electroporated dendritic cells (TriMixDC-MEL) plus ipilimumab in patients with pretreated advanced melanoma. J Clin Oncol 34: 1330-1338, 2016.

18 Reuss JE, Kunk PR, Stowman AM, Gru AA, Slingluff CL Jr and Gaughan EM: Sarcoidosis in the setting of combination ipilimumab and nivolumab immunotherapy: a case report and review of the literature. J Immunother Cancer 4: 94, 2016.
19 Bordry N, Costa-Nunes CM, Cagnon L, Gannon PO, AbedMaillard S, Baumgaertner P, Murray T, Letovanec I, Lazor R, Bouchaab H, Rufer N, Romano E, Michielin O and Speiser DE: Pulmonary sarcoid-like granulomatosis after multiple vaccinations of a long-term surviving patient with metastatic melanoma. Cancer Immunol Res 2: 1148-1153, 2014.

20 Baughman RP, Lower EE and du Bois RM: Sarcoidosis. Lancet 361: 1111-1118, 2003.

21 Thomas PD and Hunninghake GW. Current concepts of the pathogenesis of sarcoidosis. Am Rev Respir Dis 135: 747-760, 1987.

22 Statement on sarcoidosis. Joint Statement of the American Thoracic Society (ATS), the European Respiratory Society (ERS) and the World Association of Sarcoidosis and Other Granulomatous Disorders (WASOG) adopted by the ATS Board of Directors and by the ERS Executive Committee, February 1999. Am J Respir Crit Care Med 160: 736-755, 1999.

23 Lheure C, Kramkimel N, Franck N, Laurent-Roussel S, Carlotti A, Queant A, Goldwasser F, Avril MF and Dupin N: Sarcoidosis in patients treated with vemurafenib for metastatic melanoma: a paradoxical autoimmune activation. Dermatology 231: 378-384, 2015.

24 Teulings HE, Limpens J, Jansen SN, Zwinderman AH, Reitsma JB, Spuls PI and Luiten RM: Vitiligo-like depigmentation in patients with stage III-IV melanoma receiving immunotherapy and its association with survival: a systematic review and metaanalysis. J Clin Oncol 33: 773-781, 2015.

25. Balch CM, Gershenwald JE, Soong SJ, Thompson JF, Atkins MB, Byrd DR, Buzaid AC, Cochran AJ, Coit DG, Ding S, Eggermont AM, Flaherty KT, Gimotty PA, Kirkwood JM, McMasters KM, Mihm MC Jr, Morton DL, Ross MI, Sober AJ and Sondak VK: Final version of 2009 AJCC melanoma staging and classification. J Clin Oncol 27: 6199-6206, 2009.

26 Seve P, Schott AM, Pavic M, Broussolle C, Gilis L and Thomas L: Sarcoidosis and melanoma: a referral center study of 1,199 cases. Dermatology 219: 25-31, 2009.

27 Beutler BD and Cohen PR: Sarcoidosis in melanoma patients: case report and literature review. Cancers 7: 1005-1021, 2015.

28 Speiser DE, Liénard D, Rufer N, Rubio-Godoy V, Rimoldi D, Lejeune F, Krieg AM, Cerottini JC and Romero P: Rapid and strong human $\mathrm{CD} 8^{+} \mathrm{T}-$-cell responses to vaccination with peptide, IFA, and CpG oligodeoxynucleotide 7909. J Clin Invest 115: 739-746, 2005

29 Guidry C, Fricke RG, Ram R, Pandey T and Jambhekar K: Imaging of sarcoidosis: a contemporary review. Radiol Clin North Am 54: 519-534, 2016.

30 Grados A, Ebbo M, Bernit E, Veit V, Mazodier K, Jean R, Coso D, Aurran-Schleinitz T, Broussais F, Bouabdallah R, Gravis G, Goncalves A, Giovaninni M, Sève P, Chetaille B, Gavet-Bongo F, Weitten T, Pavic M, Harlé JR and Schleinitz N: Sarcoidosis occuring after solid cancer: a nonfortuitous association. Medicine 94: e928, 2015.

Received May 1, 2017

Revised May 12, 2017

Accepted May 16, 2017 